\title{
AN EXPERIMENTAL ECONOMIC STUDY OF LOSS AVERSION IN STOCK TRADING DECISIONS
}

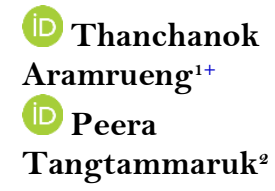

Article History

Received: 18 February 2021 Revised: 26 April 2021 Accepted: 22 November 2021 Published: 14 December 2021

\section{Keywords}

Behavioral economics Prospect theory

Loss aversion

Disposition effect

Stock trading

Binary choices model

\author{
${ }^{1,2}$ Faculty of Economics, Srinakharinwirot University, Bangkok, Thailand. \\ 'Email: thanchanok.arr@gmail.com Tel: +66902991544. \\ ${ }^{2}$ Email: peerat@g.swu.ac.th Tel: +66874565929
}

\begin{abstract}
The disposition effect is a form of behavioral bias that tends to result in investors holding on to their losing stocks for too long and selling winning stocks too soon. It can be explained by the behavioral economics theory of loss aversion. Even though many have studied this kind of behavioral bias in a variety of different countries, none of them have investigated the disposition effect in the case of Thailand. Therefore, the main objective of our study is to test the disposition effect among Thais by applying the experimental economic approaches of Weber \& Camerer (1998) and Odean (1998) whilst also including the findings from questionnaires and interviews. We set up a simulation stock trading market to test the disposition effect of participants regardless of whether they had stock trading experienced or not. Subjects were required to trade among six stocks in 14 trading periods. We also added three more periods to test how different types of news impacted the subjects' trading decisions. In addition, we analyzed socioeconomic factors that affect disposition effect behavior by using an econometric binary choice model. We found that this experiment can exhibit the disposition effect of subjects in terms of overall and individual measurement. In normal stock trading situations, we found that over $70 \%$ of subjects showed clear signs of the disposition effect, which seemed to decrease after they received fictional news.
\end{abstract}

Contribution/Originality: This study is one of very few studies that have investigated the behavioral economics of the disposition effect and the effect of news on behavioral change in the case of Thailand based on experimental methods.

\section{INTRODUCTION}

Nowadays, investing in stocks is very popular with people who have savings since it provides returns that can compete with continuous inflation, and gives higher returns than investing in other types of assets. By looking at the major world stock market indexes, such as the S\&P500, Dow Jones, Nikkei and DAX, the average stock market return for the last ten years has been around 10\% (Macrotrends, 2021). The data from The Stock Exchange of Thailand (2021) states that in the past ten years, the Thai stock market has had an average yearly return of $9.39 \%$. This leads to investment in the stock market having more appeal compared to other types of assets, since its returns can compete with the continuous rise of inflation.

However, an investment in high return assets also involves a high level of risk. Apart from uncontrollable economic and financial risks, another danger of investing in the stock market can be caused by an investor's behavioral bias. To elaborate, some people may occasionally make decisions without really considering the 
rationale, which in turn causes a result deviating from an optimal outcome. This behavioral bias also relates to the disposition effect in the behavioral economics theory of loss aversion (Kahneman \& Tversky, 1979).

The disposition effect, one principle of extending Kahneman and Tversky's prospect theory to investments, was first formally presented by Shefrin \& Statman (1985). It is a form of bias that causes investors to hold on to their losing stocks for too long and sell winning stocks prematurely. Most investors keep their losing stocks in their portfolios to avoid the pain of loss. They will wait, hoping it will eventually become profitable often because they cannot accept the reality of the situation. This effect can be explained by a value function in the S-shape (see Figure 1), that focuses on gains and losses rather than overall levels of wealth in standard utility models. The function is concave in the region of gains and convex in the region of losses. The asymmetry in curvature of the valuation function implies that people are much more sensitive to a drop in their investments when compared to equal-sized gains.
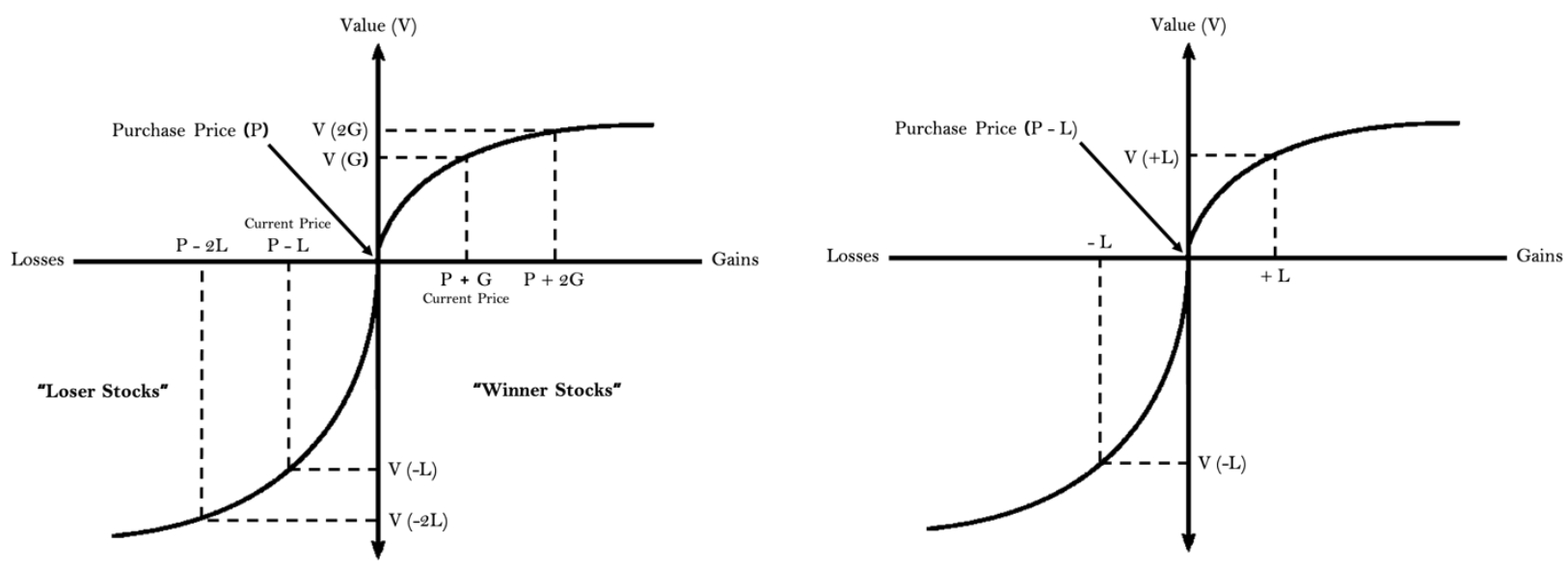

Source: Weber \& Camerer (1998).

Figure-1. How reference points create disposition effects.

Referring to Figure 1, if an investor buys stock at purchase price 'P', suddenly the value of this stock falls by amount ' $\mathrm{L}$ ', causing the stock's price to drop to $\mathrm{P}$ - L, which is called the current price, resulting in the investor then having to decide whether to hold this stock or sell it. If they decide to hold the stock, it is equally likely that its price will return to ' $\mathrm{P}$ ', which is its purchase price, or fall by amount ' $\mathrm{L}$ ' again to a price of $\mathrm{P}-2 \mathrm{~L}$, or $\mathrm{P}-\mathrm{L}-\mathrm{L}$. As a result, the value of this losing stock could be either $\mathrm{P}$ or $\mathrm{P}-2 \mathrm{~L}$ if it is held, and $\mathrm{P}-2 \mathrm{~L}$ if it is sold. If we set the purchase price ' $\mathrm{P}$ ' as a reference point, the investor will have two options - accept a certain loss with a negative value of $\mathrm{v}(-\mathrm{L})$, or gamble with a value of $\mathrm{v}(0)$ or $\mathrm{v}(-2 \mathrm{~L})$. If the investor tends to be more risk-seeking in the region of losses and the chance of returning to the purchase price 'P' (which means he breaks even) or losing another amount of ' $L$ ' are equal, he will decide to hold the stock because the pain of losing a further ' $\mathrm{L}$ ' is less than the satisfaction of recovering the purchase price 'P'. In other words, they switch their reference point from the original 'P' to the new one of $\mathrm{P}$ - L to avoid any negative feelings regarding the drop in value of their stock.

On the other hand, in the situation of a winning stock, its value rises by the amount of ' $G$ ', causing the stock's price to increase to $\mathrm{P}+\mathrm{G}$ (current price). If the investor decides to hold the stock, it is just as likely that the stock's price will fall back to ' $P$ ' or rise by the amount of ' $G$ ' again to a price of ' $P+2 G$ ' or $P+G+G$. Thus, the value of this winning stock could be either $\mathrm{P}$ or $\mathrm{P}+2 \mathrm{G}$ if it is held, and $\mathrm{P}+\mathrm{G}$ if it is sold. If the investor tends to be much more risk-averse in the realm of gains and the chances of returning to the purchase price 'P' (meaning they break even) or gains of ' $G$ ' are equal, they will decide to sell the stock to create a gain with a value of $v(G)$ rather than gambling on earning $\mathrm{v}(2 \mathrm{G})$ or $\mathrm{v}(\mathrm{O})$. 
If we consider the current price as being a reference point instead of the purchase price where the gains and losses are valued, the losing stock with a current price of ' $\mathrm{P}-\mathrm{L}$ ' will either gain $\mathrm{L}$ (if it returns to the purchase price ' $\mathrm{P}$ ') or lose an additional $\mathrm{L}$ (if it falls to $\mathrm{P}-2 \mathrm{~L}$ ). If a gamble over $\mathrm{v}(\mathrm{L})$ and $\mathrm{v}(-\mathrm{L})$ is better than $\mathrm{v}(\mathrm{O})$, the investor will hold this stock. Otherwise, they will sell it. On the other hand, the winning stock will either lose $\mathrm{G}$ (if it returns to the purchase price 'P', or gain an additional G. The investor will decide to hold it if a gamble over $v(G)$ and $v(-G)$ is better than $\mathrm{v}(\mathrm{O})$.

The behavioral economics of the disposition effect is one type of loss aversion behavioral bias that represents a situation in which an individual switches or changes a reference point in order to improve the way they feel about the situation. There are a number of international papers that attempt to apply this behavioral economic principle to study individual trading decisions and disposition effect, such as Weber \& Camerer (1998); Brown \& Kagel (2009) and Hermann, Muÿhoff, \& Rau (2017). Nevertheless, in terms of our literature review, the research that uses experimental methods to explain investment decision behavior, especially the disposition effect, is rarely found in Thailand.

This research, therefore, aims to apply the concept of behavioral economic disposition effect together with an experimental economic approach to study the case of Thailand with the belief that this behavioral bias can be found in the Thai population as well. Following the 14-period experimental framework used by Weber \& Camerer (1998), Odean (1998), and Hermann et al. (2017), we simulated a stock trading market over 14 periods to test the disposition effect of participants, and also added a further three periods (period $15-17$ ) to test the effect of news on behavioral change. The participants in this study comprised both student and working groups in Bangkok and are divided into two groups - those who have stock investment experience and those who do not. Our hope is that the study on the disposition effect topic for Thailand's stock exchange market will better our understanding about investment behavior in other dimensions.

\section{LITERATURE REVIEWS}

From studies related to human decision-making behavior, we found that the disposition effect has a different relationship with decision making.

According to a study conducted by Shefrin \& Statman (1985) which officially presented the disposition effect for the first time, fear of loss and searching for pride causes investors to hold losing stocks for too long and sell winning stocks too early. This result is consistent with the research by Weber \& Camerer (1998), which found that the disposition effect is a bias that affects the behavior of people in the stock market. Therefore, they are more likely to sell profitable assets and continue to hold lost assets. It is also in line with a study by Odean (1998), who analyzed the trading records of 10,000 individual investors. His study shows that investors are more likely to sell profitable stocks than lost stocks. The proportion that investors realize their gains was about 50 percent higher than realized losses.

Garvey \& Murphy (2004) found evidence of the disposition effect while observing the behavior of 15 professional traders. The traders tended to hold on to their shrinking stocks for too long and sell their winning stocks too soon, and this tendency to do so lowered their profitability. The research by Da Costa, Goulart, Cupertino, Macedo, \& Da Silva (2013) showed that regardless of whether the sample was experienced or not in the stock market, they still indicated the same disposition effect. However, experienced investors were typically less affected by the disposition effect than inexperienced investors. In addition, Ploner (2017) found that disposition effects exist in general risk tasks in which choices are taken sequentially; however, the disposition effect can often be reversed when choices are planned ahead. Also, research by Andersson, Holm, Tyran, \& Wengström (2016) found that, on average, the participants who make decisions on behalf of others will choose the same level of risk as their 
own decisions when excluding losses. On the other hand, if a loss occurs, making decisions on behalf of others increases the risk. This result is in line with Hermann et al. (2017), who provided experimental evidence where the investor decides on behalf of another person. They found that trading on behalf of others increases the disposition effects of traders.

Conversely, the research by Brown \& Kagel (2009) found that the disposition effect is a bias that is inconsistent with the behavior of people in the stock market. Most subjects rarely ignore profit-maximizing strategies and continue to hold stocks regardless of performance.

\section{RESEARCH METHODOLOGY}

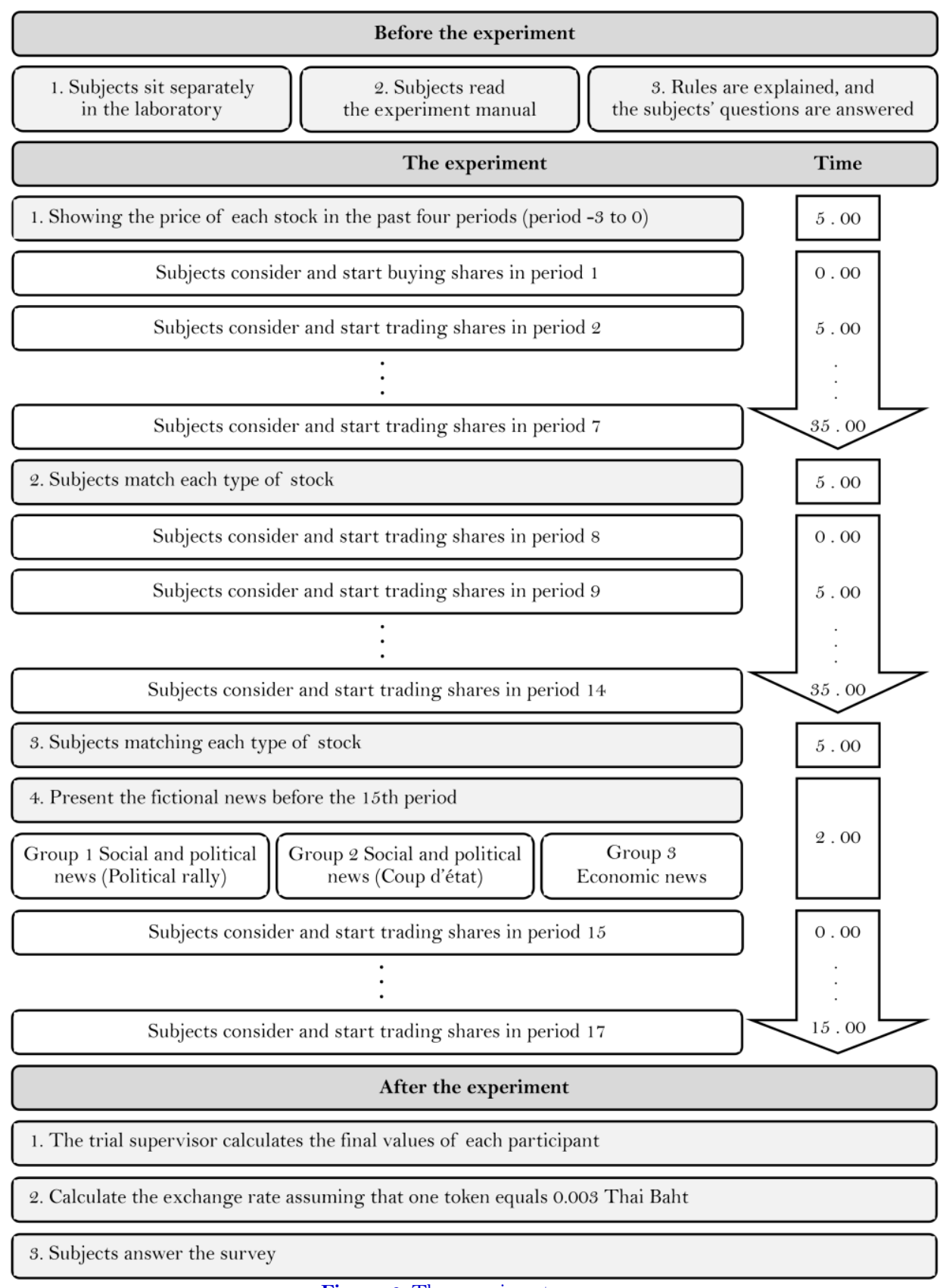

Figure-2. The experiment process.

As Figure 2 shows, the experimental method is carried out by creating a stock market model by applying the experimental methods of Weber \& Camerer (1998), Odean (1998), and Hermann et al. (2017). There are six stocks 
in the market, labeled A, B, C, D, E, and F, and there are 17 trading sessions for one experiment, which takes approximately an hour and a half. The experiment is divided into three parts - periods 1 to 7 , periods 8 to 14 , and periods 15 to 17 - where subjects can buy and sell all six shares in all 17 periods.

At the beginning of the experiment, each subject was given 10,000 tokens (a unit of experimental funds) to trade. Funds that were not invested in stocks during the experiment were counted as cash and therefore did not earn interest. In each period, subjects could buy and sell shares at announced prices with a decision time of around five minutes. The prices of shares in all 17 periods were predetermined by a random process to ensure the amount of trading shares did not affect the prices of the stocks.

The price of each stock in the past four periods (period -3 to 0) were given before the experiment started, so the subjects had an idea of the essential characteristics of the stock. For each period, the price randomization was separated into two issues - determination of price movement direction and determination of price change. To determine the direction of price action, all shares were categorized in advance based on quality levels and allocated the probability of increases and decreases in the share price, as shown in Table 1.

Table-1. Stock Characteristics.

\begin{tabular}{c|c|c|c}
\hline \multicolumn{2}{c|}{ Stock } & \multicolumn{2}{c}{ Probability of price change } \\
\hline Name & Type & Price increase & Price decrease \\
\hline A & + & $55 \%$ & $45 \%$ \\
\hline B & - & $45 \%$ & $55 \%$ \\
\hline C & -- & $35 \%$ & $65 \%$ \\
\hline D, E & $\mathrm{O}$ & $50 \%$ & $50 \%$ \\
\hline F & ++ & $65 \%$ & $35 \%$ \\
\hline
\end{tabular}

Although the subjects knew that the price of all six stocks could change, they did not know the probability of each stock rising or falling. After periods 7 and 14, the subjects were asked to guess which of the six shares represented each of the six possible types $(++,+, \mathrm{O}, \mathrm{O},-,--)$.

The size of the price change rose or fell by 1, 3, or 5 tokens, which were randomly assigned, and the possibilities of all changes were equal. The subjects' decisions were made without any additional input or information in the first and second parts of the experiment. However, before the third part (period 15) began, the fictional news was presented. The news was divided into two main categories - economic news and social \& political news and consisted of a political rally and a coup d'état. These two situations are important events that occurred in Thailand within the past two decades.

At the end of the experiment, the amount of money for each subject was calculated as the final value, which came from the sum of cash held in hand, and the final value of the returns. We set the one token exchange rate to be 0.003 THB.

In addition, interviews were conducted and the questionnaires were collected. The questionnaire was divided into two parts: In the first part, we collected general information about the subjects which consisted of gender, age, marital status, level of education, occupation, monthly income, and amount of savings per month. In the second part, we collected investment information, which included stock investment experience, the amount of investment in shares, stock trading strategies, and informational awareness.

We also had three hypotheses: the first one (H1) states that the number of shares sold would be higher for winning stocks (stocks making a gain) than for losing stocks (stocks making a loss). Therefore, we determined the gains or losses by comparing the purchase price with the reference price. There were two possible reference prices: using the purchase price as a reference or using the previous period's price as a reference. Regarding the method of using the purchase price as a reference, we calculated this by applying two different accounting principles — First- 
In-First-Out (FIFO), and average price. The FIFO principle assumes that the subjects will sell their shares in the order in which they were purchased (shares purchased first are sold first), whereas the average price approach identifies the purchase price as the weighted average of all purchase prices.

Furthermore, we identified the disposition effects on an individual level by determining the proportion of gains realized (PGR) and the proportion of losses realized (PLR). We also evaluated the disposition effect with the 'alpha' measure.

Our second hypothesis (H2) states that trading volume is positively correlated with the size of price changes, which rise or fall by 1, 3, or 5 tokens, and we assumed that the trading volume was designated as the total number of shares bought and sold. A number of studies, such as Ying (1966) and Cornell (2000), found that trading volume has a positive relationship with price change. A large trading volume should be related to a rise in price, while a small trading volume should be related to a fall in price.

Last, to test the third hypothesis (H3), we used a binary choice model to analyze socioeconomic factors affecting disposition effect behavior. The dependent variable is binary, which is equal to one for all observations in the data where the disposition effect is exhibited, and zero for the remaining observations, which are shown in the following equation:

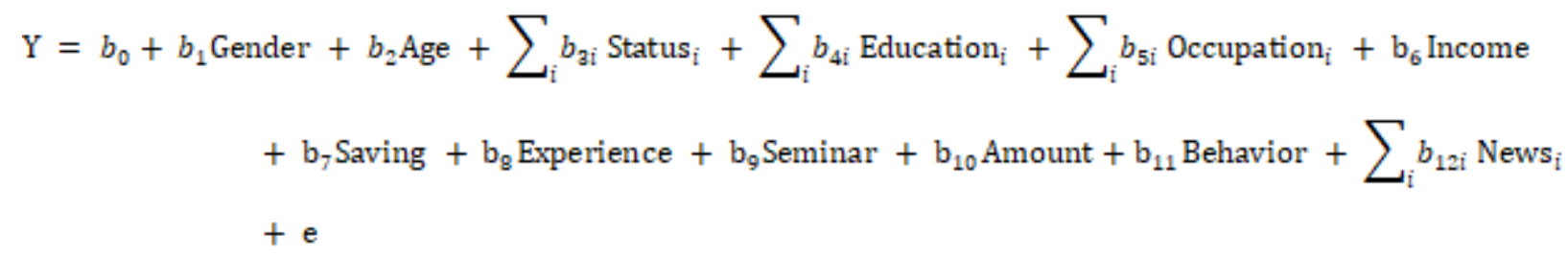

The independent variables are as follows: Gender (males are coded as 0, and females are coded as 1), age, status (single (base), married, divorced, and widowed), education (lower than a bachelor's degree (base), bachelor's degree, and higher than a bachelor's degree), occupation (university student (base), private employee, government official, self-employed, and others), income (average income per month), savings (average saved per month), investing experience (experienced are coded as 0 , and inexperienced are coded as 1), seminars on stock market investing and training experience (experienced are coded as 0 , and inexperienced are coded as 1), amount (investment amount), behavior after seeing the fictional news (changed are coded as 0 , and unchanged are coded as 1), news - the categories of fictional news given to subjects (political rally (base), coups d'état, and economic news).

\section{RESULTS}

\subsection{The Characteristics of the Subjects}

Fifty-one females and thirty-nine males attended the experiment. Most (72.22\%) of the subjects had no experience in stock investing, although about half of them (52.31\%) were interested in stock investing at the highest level. Focusing on training experience, it turned out that $62.22 \%$ of the subjects had never attended stock market investing training or seminars. The majority of the investment objectives prioritized by the subjects were capital gains, then long-term growth, and dividends. Technology stocks were the most popular categories of stocks for experienced subjects to invest in, while inexperienced subjects were mainly interested in financial stocks.

\subsection{Hypothesis Testing for Disposition Effects}

This experiment consisted of three hypotheses (H1, H2, and H3), as shown in Figure 3. We measured H1 in two ways, overall and individual. When a share is sold, there are two different accounting principles to find the sale price: using the purchase price as a reference price and using the previous period's price as a reference price. Therefore, to identify the individual disposition effect needed to rely on two measurements, we calculated the 
individual-level disposition effects as the difference between the PGR and PLR using the 'alpha' measure. The second hypothesis $\left(\mathrm{H}_{2}\right)$ states that trading volume is positively correlated with the size of price changes. Last, we analyzed factors affecting the disposition effect (H3) by using a binary choice model.

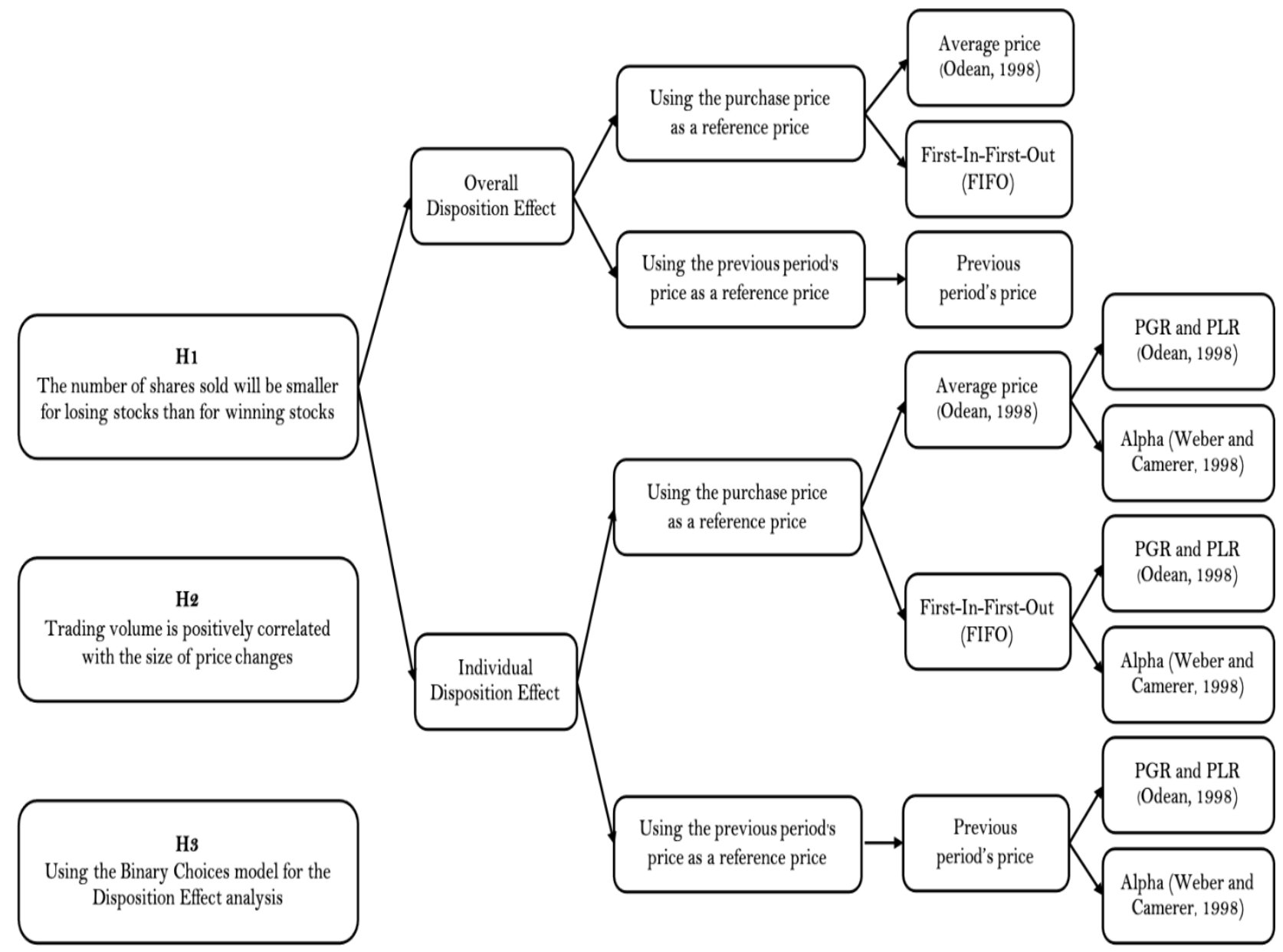

Figure-3. The process of hypothesis testing.

Table 2 shows the number of shares that were sold during the experiment which resulted in the subjects making a profit, breaking even, or making a loss. When considering each stock in the market, it was found that subjects decided to sell winning stocks more than losing stocks. This supports H1 and, in relation to the disposition effect, that subjects tend to sell their winning stocks too early and hold onto their losing stocks for too long.

Regardless of what method is used, the results are the same. In fact, when interviewing subjects about the strategies that they used during the experiment, we found that most subjects used the strategy which was similar to the previous period's price method as they think it is the easiest way to calculate the profit. 
Humanities and Social Sciences Letters, 2021, 9(4): 417-429

Table-2. Overall disposition effect measurement.

\begin{tabular}{|c|c|c|c|c|c|c|c|c|c|c|c|c|c|c|c|}
\hline \multirow{2}{*}{ Stock Type } & \multirow{2}{*}{$\begin{array}{c}\text { Trading } \\
\text { result }\end{array}$} & \multicolumn{2}{|c|}{ A } & \multicolumn{2}{|c|}{ B } & \multicolumn{2}{|c|}{ C } & \multicolumn{2}{|c|}{ D } & \multicolumn{2}{|c|}{ E } & \multicolumn{2}{|c|}{$\mathbf{F}$} & \multicolumn{2}{|c|}{ Overall } \\
\hline & & Total & $\%$ & Total & $\%$ & Total & $\%$ & Total & $\%$ & Total & $\%$ & Total & $\%$ & Total & $\%$ \\
\hline \multirow[b]{2}{*}{ Average price } & Gain & 1,565 & 62.45 & 1,315 & 52.85 & 676 & 50.15 & 957 & 39.25 & 1,000 & 57.47 & 2,189 & 74.35 & 7,702 & 57.20 \\
\hline & Even & $\mathrm{O}$ & 0.00 & 3 & 0.12 & $\mathrm{O}$ & 0.00 & 5 & 0.21 & 40 & 2.30 & 20 & 0.68 & 68 & 0.51 \\
\hline \multirow{3}{*}{$\begin{array}{c}\text { First-In-First- } \\
\text { Out (FIFO) }\end{array}$} & Gain & 1,451 & 57.44 & 1,352 & 54.34 & 635 & 46.76 & 990 & 40.08 & 965 & 55.84 & 2,394 & 80.01 & 7,787 & 57.42 \\
\hline & Even & 180 & 7.13 & 46 & 1.85 & 68 & 5.01 & 92 & 3.72 & 114 & 6.60 & 167 & 5.58 & 667 & 4.92 \\
\hline & Loss & 895 & 35.43 & 1,090 & 43.81 & 655 & 48.23 & 1,388 & 56.19 & 649 & 37.56 & 431 & 14.41 & 5,108 & 37.66 \\
\hline \multirow{3}{*}{$\begin{array}{c}\text { Previous } \\
\text { period's price }\end{array}$} & Gain & 1,551 & 61.52 & 1,772 & 71.37 & 815 & 60.69 & 1,481 & 60.08 & 1,142 & 66.20 & 2,257 & 75.56 & 9,018 & 66.68 \\
\hline & Even & $\mathrm{O}$ & 0.00 & $\mathrm{O}$ & 0.00 & $\mathrm{O}$ & 0.00 & $\mathrm{O}$ & 0.00 & $\mathrm{O}$ & 0.00 & $\mathrm{O}$ & 0.00 & $\mathrm{O}$ & 0.00 \\
\hline & Loss & 970 & 38.48 & 711 & 28.63 & 528 & 39.31 & 984 & 39.92 & 583 & 33.80 & 730 & 24.44 & 4,506 & 33.32 \\
\hline
\end{tabular}


There are exceptions for the D shares, which were calculated by the average price method and First-In-FirstOut (FIFO) method. This might be caused by the past four periods' prices (period -3 to 0 ) that were presented to the subjects before the experiment began, which showed an upward trend of D's share price. This led most subjects to buy a lot of $\mathrm{D}$ shares in period 1 . After that, the price of $\mathrm{D}$ shares continued to drop, especially after period 8 . Thus, if the subjects sell D shares during the second part (periods 8 through 14) or the third part (periods 15 through 17) of the experiment, almost all sales are losses because the price of D shares in period 14 and period 17 was lower than period 1 (the price that most subjects bought).

Table-3. Individual disposition effect measurement.

\begin{tabular}{|c|c|c|c|c|c|c|c|c|}
\hline & \multicolumn{4}{|c|}{ The individual-level DE measure } & \multicolumn{4}{|c|}{ Alpha measure } \\
\hline & \multicolumn{2}{|c|}{ Before } & \multicolumn{2}{|c|}{ After } & \multicolumn{2}{|c|}{ Before } & \multicolumn{2}{|c|}{ After } \\
\hline & Total & $\%$ & Total & $\%$ & Total & $\%$ & Total & $\%$ \\
\hline Average price & 69 & 76.67 & 63 & 70.00 & 68 & 75.56 & 56 & 62.22 \\
\hline $\begin{array}{l}\text { First-In-First-Out } \\
\text { (FIFO) }\end{array}$ & 73 & 81.11 & 67 & 74.44 & 75 & 83.33 & 61 & 67.78 \\
\hline Previous period's price & 64 & 71.11 & 72 & 80.00 & 66 & 73.33 & 68 & 75.56 \\
\hline
\end{tabular}

The individual disposition effect measurements are shown in Table 3. This table shows the comparison between the number of subjects that showed disposition effects before and after seeing the fictional news by using the individual-level disposition effect and alpha measurements. It was found that more than $70 \%$ of subjects showed a disposition effect before seeing the fictional news, while after seeing the fictional news, more than $60 \%$ of subjects experienced a disposition effect. Considering the decrease in the number of subjects, we can assume that the fictional news reduced the disposition effect in the subjects. In the third part of the experiment (periods 15 through to 17), the stock price suddenly dropped and the majority of subjects decided to sell most of the stocks in their portfolios. This represents behavior which is in contrast to that of the disposition effect.

Table-4. Marginal effect logistic regression.

\begin{tabular}{|c|c|c|c|c|c|c|}
\hline \multirow[b]{2}{*}{ Estimation Methods } & \multicolumn{2}{|c|}{ Average price } & \multicolumn{2}{|c|}{ First-In-First-Out (FIFO) } & \multicolumn{2}{|c|}{ Previous period's price } \\
\hline & $\begin{array}{c}\text { DE } \\
\text { Method }\end{array}$ & $\begin{array}{c}\text { Alpha } \\
\text { Method }\end{array}$ & $\begin{array}{c}\text { DE } \\
\text { Method }\end{array}$ & $\begin{array}{l}\text { Alpha } \\
\text { Method }\end{array}$ & $\begin{array}{c}\text { DE } \\
\text { Method }\end{array}$ & $\begin{array}{c}\text { Alpha } \\
\text { Method }\end{array}$ \\
\hline Gender & 0.0360 & 0.0540 & 0.0530 & -0.1094 & 0.0203 & -0.1201 \\
\hline Age & 0.0094 & -0.0107 & 0.0054 & -0.0009 & 0.0112 & 0.0120 \\
\hline Status (Married) & -0.1163 & 0.0765 & -0.1783 & 0.0404 & -0.1217 & -0.0501 \\
\hline $\begin{array}{l}\text { Education (Bachelor's } \\
\text { Degree) }\end{array}$ & -0.0385 & -0.1140 & -0.0208 & -0.0354 & -0.0709 & -0.0888 \\
\hline $\begin{array}{l}\text { Education (Higher than a } \\
\text { Bachelor's degree) }\end{array}$ & -0.0407 & -0.0218 & & 0.1667 & 0.1126 & 0.1655 \\
\hline $\begin{array}{l}\text { Occupation (Private } \\
\text { employee) }\end{array}$ & -0.0871 & 0.1214 & $-0.2418^{*} *$ & -0.0977 & -0.1640 & -0.1511 \\
\hline \multicolumn{7}{|l|}{$\begin{array}{l}\text { Occupation (Government } \\
\text { official) }\end{array}$} \\
\hline Occupation (Self-employed) & -0.2017 & 0.2107 & -0.2477 & -0.3198 & $-0.5567 * *$ & $-0.4327^{*}$ \\
\hline \multicolumn{7}{|l|}{ Occupation (Others) } \\
\hline Income (1:1000 Thai Baht) & 0.0023 & 0.0011 & $-0.0088^{* *}$ & -0.0039 & 0.0037 & 0.0033 \\
\hline Saving (1:1000 Thai Baht) & -0.0125 & -0.0060 & $0.0475^{* * * *}$ & 0.0152 & -0.0134 & $0.0255^{* * *}$ \\
\hline Experience & -0.0889 & -0.0166 & 0.1576 & 0.1603 & 0.1259 & $0.2486^{*}$ \\
\hline Seminar & -0.0530 & $-0.3304 * * *$ & 0.0581377 & -0.128084 & -0.0693189 & $-0.2661^{* * *}$ \\
\hline Amount & -0.0006 & -0.0033 & 0.0030 & -0.0027 & 0.0023 & 0.0017 \\
\hline Behavior & $0.3092^{*}$ & 0.2667 & 0.0000 & $0.5231^{* * *}$ & 0.1614 & 0.2118 \\
\hline News (coup d'état) & -0.1198 & 0.1063 & $-0.1539^{* *}$ & 0.0333 & -0.1454 & -0.1267 \\
\hline News (economic news) & $-0.2040^{*}$ & -0.0421 & $-0.2982^{* * * *}$ & 0.0316 & $-0.2629 * * *$ & -0.1525 \\
\hline
\end{tabular}

Notes: * *** and *** indicate significance at $90 \%, 95 \%$ and $99 \%$ confidence levels, respectively. 
Next, we tested $\mathrm{H} 2$, which hypothesizes that the trading volume is positively correlated with the size of price changes. We counted the volume of shares traded when the price changed $(1,3$, or 5 tokens) and tested the statistical significance using the t-test. There were twelve pairs in which the size of price changes were significant at the 0.05 level meaning that $\mathrm{H}_{2}$ cannot be rejected. We can see from the analysis that the trading volume when the price rises significantly (falls) is greater than the trading volume when the price rises (falls) by a lesser degree (2), and that the trading volume when the price rises was greater than the trading volume when the price falls, which indicates that the change in the size of the price affects the trading decisions of the subjects.

According to the estimation in the logit model, the disposition effect is significantly affected by nine variables (see Table 4). The first variable is an occupation which shows that both private employees and the self-employed are less likely to show behavior associated with the disposition effect, i.e., if the subjects are private employees or selfemployed, the probability of them holding on to losing stocks for too long and selling ones that are doing well will decrease compared to those who are students. This result is consistent with the research of Dhar \& Zhu (2009), which found that the investors in professional occupations who have technical, managerial, or administrative careers will exhibit a smaller disposition effect than the investors whose occupations are non-professional. In this case, we could say that private employees and the self-employed who mostly deal with a systematic work process were more likely to have favorable outcomes in the stock trading market compared to students. However, the difference in the occupational background of each person could affect people's perceptions and risk preferences in different ways.

The average monthly income also has a negative correlation to the disposition effect at the $95 \%$ confidence level. As the average monthly income increases, the subjects experience a lesser disposition effect. If the subjects have an increase in average monthly income by 1,000 THB, the probability of the disposition effect will decrease by 0.0088 , or roughly $0.9 \%$. This result is in line with the research by Dhar \& Zhu (2009), who found that high-income investors exhibited lower disposition effects than low-income investors. From this it can be inferred that subjects with a higher level of income are those who have more available funds for investing. Hence, they are more riskseeking and can accept bad decisions more easily than the lower-income subjects. In addition, high-income subjects may have the ability to access more financial information than low-income subjects. For instance, higher earners are more likely to have contacts who are financial experts. Conversely, our experiments are opposed to the research of Dhar \& Zhu (2009) which stated that wealthier people exhibit fewer disposition effects. Our results show that average monthly savings have a positive correlation to the disposition effect. The probability of the disposition effect will increase by between 0.0255 and 0.0475 , or approximately 3 to 5 percent, if the subjects increase their average monthly savings by 1,000 THB.

When considering investment information, there are two significant variables. The first variable is when the stock investment experience, which uses the average price method, has a negative correlation to the disposition effect. This result is consistent with the research by Weber \& Welfens (2007), Feng \& Seasholes (2005), Dhar \& Zhu (2009), and Da Costa et al. (2013), which suggests that more experience will help to lower the disposition effect of most investors. However, this method is not statistically significant. The other methods show that the stock investment experience has a positive correlation to the disposition effect, especially the previous period's price method, which is statistically significant with a confidence level of $90 \%$. If the subjects have more experience in stock investing, they are likely to have a $25 \%$ increase in the disposition effect. On the other hand, subjects who have more experience in stock market investing training are likely to have a negative correlation to the disposition effect.

The fictional coup d'état news along with economic issues are the variables that have statistical significance. The subjects who received the coup d'état news will show a reduction in the chances of the disposition effect by 0.1539 , or approximately 15 percent, compared to those who received the fictional news of a political rally. 
Meanwhile, the subjects who received news relating to the economy will have a drop in the chance of the disposition effect by $0.2040,0.2982$, and 0.2629 , or approximately at a probability in the range of 20 to 30 percent compared to those who received news about political rallies. The behavior of subjects after seeing the fictional news had a positive correlation to the disposition effect in that the subjects who did not change their behavior after seeing the fictional news are more likely to experience the disposition effect.

\subsection{Matching the Stocks' Characteristics}

In terms of guessing the characteristics of all six stocks, it was found that over half of the subjects (61.11\%) ranked $\mathrm{F}$ shares as the best stocks since the first round of guessing (after period 7 ). In the second round of guessing (after period 14), 83.33\% of subjects were able to correctly rank F shares. Only $2.22 \%$ of subjects were able to rank all stocks correctly after period 7 with the percentage increasing to $5.56 \%$ after period 14 .

One interesting observation from this experiment is that only $49.09 \%$ of subjects correctly guessed the $\mathrm{F}$ shares as being the best quality stocks (or $30 \%$ of all subjects) and consequently decided to buy more of them in period 8 . Nevertheless, even though they perceived that $\mathrm{F}$ shares tend to go up in price, they did not buy as many $\mathrm{F}$ shares as they should have. This could be linked to the loss aversion bias in which subjects have the tendency to avoid losses, especially when the price of $\mathrm{F}$ shares is dramatically higher. From the interviews, some subjects said that the steadily rising price of $\mathrm{F}$ shares made them reluctant to buy more. They were afraid of huge losses if the price of $\mathrm{F}$ shares started to fall in the future. Therefore, they decided to buy other shares instead, even though they realized that the other shares were not as good as the F shares. In other words, it is safe to say that these subjects presented risk-averse characteristics

\subsection{News Effects}

After receiving the fictional news, the subjects who saw news about a political rally were the group with the highest tendency to sell their shares, followed by the group that were shown coup d'état news, then economic news relating to Thai Baht fluctuation. About 33.33\% of subjects sold their shares in period 15 , meanwhile $5.56 \%$ of subjects decided to sell all their shares and leave their portfolio empty during the last two periods. This behavior directly contradicts the disposition effect that subjects should hold on to losing stocks. We can summarize from the subjects interviewed that the fictional news made them feel panicked. Therefore, they hurried to sell their shares despite the fact these shares gave negative returns - worrying that they may face enormous pain or lose everything if they continued to hold these shares.

\section{CONCLUSION}

This paper examines the investment behavior on the disposition effect in the stock exchange market in Thailand. We explored the subjects' behavior through an experimental economic method and collected data via questionnaires and interviews.

The major conclusion of the study is that the simulation of trading stocks within this simple market can reflect the existence of the disposition effect - subjects tend to sell the winning stocks more than the losing stocks. Moreover, when considering individual subjects, it was found that more than $70 \%$ of subjects in this experiment were influenced by the disposition effect in normal trading situations. Our findings are aligned with the results of Weber \& Camerer (1998). Although the number sampled is small, the findings strongly suggest that this type of bias behavior can be found in the Thai population as well.

We also found that the perception of the probability price change rarely influenced the subjects' decisions to buy more shares. For example, most subjects perceived that F shares have a positive trend; however, they still 
avoided buying more $\mathrm{F}$ shares or did buy not as many as they should have. From the interviews, some of them mentioned that they did not dare to buy because the price of $\mathrm{F}$ shares was already too high. Some people did not dare to take risks in case the price of $\mathrm{F}$ shares falls in the future, despite the fact that the probability of the price of $\mathrm{F}$ shares decreasing was the lowest compared to other stocks.

The size of price changes also affected the trading volume of this experiment. We found that the trading volume of shares was greater when there was a large change in price size as opposed to when there was only a small change.

Our paper shows that whether it is the First-In-First-Out (FIFO), the average price, or the previous period's price method, the results regarding the disposition effect were similar. We noticed that the FIFO method was the most realistic one when it came to reflecting profit. Most of the subjects who used a strategy similar to this method were those who had investment experience, and this was a relatively small number. The previous period's price was the easiest method to compare the profits of stocks. Most subjects also used this method to quickly calculate their profits before deciding to hold or sell their shares. This method is the most likely to be able to identify the decisionmaking behavior of the subjects in this experiment. The most difficult method to calculate gains or losses is the average price method.

Some Thai personality traits may have contributed to increasing the behavioral bias. For example, some Thai people believe in fate, making them more likely to accept their current state and be satisfied with what they have without struggling. However, this characteristic seems to an obstacle in terms of investing. Meanwhile, many people want to invest in the stock market because they believe that it is an easy way to make money without much effort. They only focus on how to get profit or get rich quickly without planning. When they face a loss, it is difficult to accept. Therefore, many people decide to keep their losing stock because they are scared that they will lose more, or make a mistake, and they hope that fate will be kinder to them in the future. On the other hand, when their shares are profitable, they often decide to sell in order to feel that they have achieved success. This behavior was evident in our research and clearly shows the disposition effect in the decision making of these Thai subjects.

Finally, we found that the shock from outside the market which is a negative external factor appears to have an impact on the subject's disposition effect behavior. After receiving the fictional news, most of them showed that they were quite worried about it. From the interviews, they felt that the political news was closer to their lives and easier to understand compared to the Thai Baht fluctuation news. Throughout their lifetimes, the military coups d'état and several political rallies had occurred at least once. They could immediately imagine that a terrible incident would surely happen again after this. Whenever these situations occurred, or even if a rumor circulated, it often shook their confidence and affected their decisions. Therefore, most of them decided to sell their shares regardless of their past playing habits because they believe that the stock market index tends to be negative and does not recover quickly. While the subjects who received economic news took some time to consider the implications after the Thai Baht had appreciated, those with a knowledge of economics were better equipped to predict how the situation would progress. Some of them decided to sell their shares immediately, but many more waited to see the results of the next round first. For future research, it would be interesting to increase the number of subjects and apply the idea of simulation trading to other types of markets that have price fluctuations, such as the cryptocurrency market, in order to present loss aversion and other bias. Hopefully, this research can help individual investors, or those who wish to invest, to understand the behavioral biases that can lead them to making mistakes. By being more aware of the psychology behind their decisions, they will be able to minimize risk on their trading activities and gain investment returns. 
Funding: This study received no specific financial support.

Competing Interests: The authors declare that they have no competing interests.

Acknowledgement: Both authors contributed equally to the conception and design of the study.

\section{REFERENCES}

Andersson, O., Holm, H. J., Tyran, J. R., \& Wengström, E. (2016). Deciding for others reduces loss aversion. Management Science, 62(1), 29-36.

Brown, A. L., \& Kagel, J. H. (2009). Behavior in a simplified stock market: The status quo bias, the disposition effect and the ostrich effect. Annals of Finance, 5(1), 1-14. doi: https://doi.org/10.1007/s 10436-007-0092-0

Cornell, B. (2000). The relationship between volume and price variability in futures markets. The Journal of Futures Markets, 20(1), 5-18. doi: https://doi.org/10.1002/(sici)1096-9934(200001)20:1<5::aid-fut3>3.0.co;2-r

Da Costa, J. N., Goulart, M., Cupertino, C., Macedo, J. J., \& Da Silva, S. (2013). The disposition effect and investor experience. Journal of Banking \& Finance, 37(5), 1669-1675. doi: https://doi.org/10.1016/j.jbankfin.2012.12.007

Dhar, R., \& Zhu, N. (2009). Up close and personal: An individual level analysis of the disposition effect (No. ysm269). Yale School of Management.

Feng, L., \& Seasholes, M. S. (2005). Do investor sophistication and trading experience eliminate behavioral biases in financial markets? Review of Finance, 9(3), 305-351. doi: https://doi.org/10.1007/s10679-005-2262-0

Garvey, R., \& Murphy, A. (2004). Are professional traders too slow to realize their losses? Financial Analysts Journal, 60(4), 3543. doi: https://doi.org/10.2469/faj.v60.n4.2635

Hermann, D., Muÿhoff, O., \& Rau, H. (2017). The disposition effect when deciding on behalf of others. Cege Discussion Papers, No. 332.

Kahneman, D., \& Tversky, A. (1979). Prospect theory: An analysis of decision under risk. Econometrica, 47(2), $263-292$.

Macrotrends, L. (2021). S\&P 500 historical annual returns. Retrieved from https://www.macrotrends.net/2526/sp-500historical-annual-returns. [Accessed January 26, 2021].

Odean, T. (1998). Are investors reluctant to realize their losses? The Journal of Finance, 53(5), 1775-1798. doi: https://doi.org/10.1111/0022-1082.00072

Ploner, M. (2017). Hold on to it? An experimental analysis of the disposition effect. Judgment and Decision Making, 12(2), 118 127.

Shefrin, H., \& Statman, M. (1985). The disposition to sell winners too early and ride losers too long: Theory and evidence. The Journal of Finance, 4O(3), 777-790. doi: https://doi.org/10.1111/j.1540-6261.1985.tb05002.x

The Stock Exchange of Thailand. (2021). Market Statistics. Retrieved from https://www.set.or.th/th/market/market_statistics.html. [Accessed January 26, 2021 ].

Weber, M., \& Camerer, C. F. (1998). The disposition effect in securities trading: An experimental analysis. Journal of Economic Behavior \& Organization, 33(2), 167-184. doi: https://doi.org/10.1016/s0167-2681(97)00089-9

Weber, M., \& Welfens, F. (2007). An individual level analysis of the disposition effect: empirical and experimental evidence (No. 07-45). Sonderforschungsbereich 504, Universität Mannheim.

Ying, C. C. (1966). Stock market prices and volumes of sales. Econometrica: Journal of the Econometric Society, 34(3), 676-685. doi: https://doi.org/10.2307/1909776

Views and opinions expressed in this article are the views and opinions of the author(s), Humanities and Social Sciences Letters shall not be responsible or answerable for any loss, damage or liability etc. caused in relation to/arising out of the use of the content. 